\title{
Migration and Segregation Phenomena of a Silicone Additive in a Multilayer Organic Coating.
}

\author{
Steven J. Hinder ${ }^{1 *}$, Chris Lowe ${ }^{2}$, James T. Maxted ${ }^{2}$ and John F. Watts ${ }^{1}$ \\ 1 The Surface Analysis Laboratory, School of Engineering, University of Surrey, Guildford, Surrey GU2 7XH, UK. \\ 2 Becker Industrial Coatings Ltd, Goodlass Road, Speke, Liverpool L24 9HJ, UK.
}

*Correspondence to: Dr Steven J. Hinder, The Surface Analysis Laboratory, School of Engineering, Mail Stop H6, University of Surrey, Guildford, Surrey GU2 7XH, UK.

Email: s.hinder@surrey.ac.uk Fax:+44 (0) 1483686291. 


\section{Abstract :}

The migration and segregation of a minor silicone containing additive in a multilayer, organic coating system has been investigated by X-ray photoelectron spectroscopy (XPS) and time-of-flight secondary ion mass spectrometry (ToF-SIMS). The silicone containing additive employed was the most compatible thermally stable, polyester modified poly(dimethyl siloxane) (PDMS) flow agent. A polyester/polyurethane (PU) based primer and a poly(vinylidene difluoride) (PVdF) based topcoat on an aluminium substrate were used as a model, multilayer, organic coating system. XPS and SIMS characterisation of the PU primer formulation (with and without addition of the PDMS based flow agent), confirmed that the PDMS based flow agent segregated to the PU primers air/coating surface. Characterisation of the PVdF topcoats air/coating surface, after application and curing over the PU primers, revealed the presence of the PDMS based flow agent at the PVdF air/coating surface when the topcoat was applied to the PU primer containing the PDMS based flow agent. Ultra-low-angle microtomy (ULAM) was employed to produce an ultra-lowangle taper that passes through the entire thickness of the PVdF topcoat $(\sim 20 \mu \mathrm{m})$. XPS linescan analysis along the ULAM taper indicated that the PDMS based flow agent had migrated from the PU primer surface into the bulk of the PVdF topcoat. Analysis of the shape of the silicon concentration profile revealed the existence of a silicon concentration gradient and indicated that the PDMS based flow agent was segregating towards the PVdF topcoats air/coating surface. Such migration and segregation phenomena have major implications for formulators in the coatings/paint industries. 


\section{Keywords :}

Time-of-Flight Secondary Ion Mass Spectrometry; X-ray Photoelectron

Spectroscopy; Ultra-low-angle Microtomy; Multilayer Organic Coatings:

Compositional Depth Profiling.

\section{Running Headline :}

Migration and Segregation of a Si Additive in a Multilayer Coating. 


\section{Introduction :}

Steel and aluminium substrates protected by organic coatings, such as those employed in the coil coating process, are used extensively in a wide range of commercial and industrial applications. These applications include architectural cladding for walls and roofs, caravans, and household/domestic appliances. The coatings employed must exhibit a wide range of diverse properties. They must be able to withstand the forces applied during the sheet forming processes without cracking and without loss of coating-metal adhesion and yet must also resist corrosion and photodegradation for 25 years or more. Because of this coil coating formulations may be considered to be one of the most technologically advanced of all coatings/paint systems.

The use of small quantities of minor additives in a coating formulation may have a profound effect on the surface properties exhibited by a polymeric coating when it is applied to a metallic substrate. The segregation to a coatings surfaces $[1,2,3]$ and interfaces [4] of components and additives included in coating/paint formulations is a well documented phenomena. Indeed, additives are often included in formulations with the express intent that the additive should migrate to the coating/paint surface so at to perform its specified function (or functions). Such functions may include levelling, [5] anti-cratering, [6] enhancing substrate wetting and improving flow. Perhaps the additive used most commonly is a flow/levelling agent. Such agents influence the protective properties of a coating on a metal substrate by improving 
wetting and therefore work of adhesion but they also enhance the visual appearance and thus the decorative effect of the coating.

A range of materials have been developed for use as flow and levelling agents in coating and paint formulations, the materials most commonly employed are polymers, fluorosurfactants, solvents with high evaporation index values and silicones. [7] Homopolymeric and copolymeric polyacrylates are the most commonly employed polymeric materials for flow/levelling agents, although cellulose acetobutyrate and other speciality polymers have also been used. [7] Fluorosurfactants provide a very strong reduction of surface tension and thus can be incorporated in very small quantities in coating and paint formulations, however, problems with foam stabilisation and decreased intercoat adhesion may result from their use. A range of solvents have been employed in coating/paint formulations to improve levelling, unfortunately, such solvents are not very effective at increasing surface flow. Typically, solvents employed to increase surface levelling are used in combination with an additive that improves surface flow. [7] Silicones (in the form of siloxanes) have been used in coating/paint formulations since the 1950's. Unmodified, backbone modified and side-chain modified polysilxoanes have all been utilised as flow/levelling agents. They provide excellent reduction of surface tension thus enhancing surface flow and substrate wetting. [7] The main problem for coil coatings is their tendency to break down above $180^{\circ} \mathrm{C}$ to the original silicone oil resulting in craters. Typical peak metal temperatures during the coil coating process are above $210^{\circ} \mathrm{C}$. 
Surface active additives such as flow/levelling agents in coating/paint formulations are a standard component in the armoury of the coatings/paint formulator. The final location of a surface active agent upon curing of a single layer coating is relatively easy to determine. However, the fate of surface active agents is not always clear where multilayer coatings are concerned. Does the surface active agent on the surface of a primer remain bound to the primer coating bulk and become an integral part of the coating-coating interface in a multilayer organic coating? Alternatively, does the surface active agent added to a primer diffuse or migrate into a topcoat upon application, thus potentially modifying the properties exhibited by the topcoat? The answers to such questions are of fundamental importance to those concerned with developing coating and paint formulations.

In the work described in this paper XPS and ToF-SIMS have been employed to characterise a PU primer formulation, with and without the addition of a siloxane based, surface active flow agent. These same techniques were also employed to characterise the air/coating surface of a PVdF based topcoat which had been applied to each of the PU primer formulations. The ULAM technique [8] was employed to impart an ultra-low-angle taper through a PVdF topcoat and PU primer multilayer, polymeric coating system. XPS linescan analysis along the ULAM taper enabled a compositional depth profile describing changes in elemental concentration through the entire multilayer coating system $(\sim 25 \mu \mathrm{m})$ to be acquired. 


\section{Experimental :}

\section{Materials and Methods}

The model PU primer/PVdF topcoat system used in this work was applied to aluminium substrates. The primer is based on a typical commercial, 'real world' polyester/polyurethane primer formulation, which is comprised of a blocked diisocyanate and an aromatic polyester resin. Additionally, the PU primer formulation contains a yellow, anticorrosive pigment (strontium chromate). The PU primer (with and without the PDMS based flow agent) was applied to get a $5 \mu \mathrm{m}$ dry film thickness and cured by stoving with an oven dwell time of $25 \mathrm{~s}$ at a peak metal temperature of $241^{\circ} \mathrm{C}$. All PU primers coatings were quenched immediately after stoving in demineralised water. The model PVdF topcoat employed is also based on a typical commercial, 'real world' PVdF topcoat formulation, which is principally composed of a polyvinylidene fluoride resin blended with acrylic co-polymers. The fluoropolymer provides high durability performance and chemical resistance, whilst the acrylics enhance the film forming properties. The PVdF topcoat formulation employed in these studies was pigmented with mainly blue and white pigments. The PVdF topcoat was applied to get a dry film thickness of $20-22 \mu \mathrm{m}$ and cured by stoving with an oven dwell time of $30 \mathrm{~s}$ at a peak metal temperature of $254^{\circ} \mathrm{C}$.

The samples analysed were cured multilayer coatings applied to aluminium panels $(\sim 16 \mathrm{~cm} \times 10 \mathrm{~cm} \times 0.5 \mathrm{~cm})$. For the characterisation of the model PU primer and PVdF topcoat surfaces by XPS, a disc $\sim 1 \mathrm{~cm}$ in diameter was punched from the sample panel and analysed. To prepare specimens for ULAM processing samples $\sim 1$ 
$\mathrm{cm}^{2}$ were cut from the panel using an industrial guillotine. To ensure that any burrs or asperities formed at the rear of the sample by the guillotining process were removed, the rear of each specimen was polished using a silicon-carbide abrasive paper (Struers, Glasgow, UK). At all times great care was taken to ensure the procedures used to cut the specimen from the sample panel and to prepare the specimen for ULAM processing resulted in the specimen remaining flat.

\section{Ultra-low-angle Microtomy}

A schematic of the ULAM apparatus employed in the production of ultra-low-angle tapers is presented in Figure 5. The ULAM processing of samples was carried out on a Microm HM355S motorised rotary microtome (Optech Scientific Instruments, Thame, UK) equipped with a standard specimen clamp and a tungsten carbide knife. The ultra-low-angle sectioning blocks $\left(\sim 3.5 \times 3.5 \times 0.7 \mathrm{~cm}^{3}\right)$ were manufactured inhouse from high-quality steel. The ultra-low-angle sectioning blocks have one $3.5 \times$ $3.5 \mathrm{~cm}^{2}$ tapered face raised by a defined amount (in $\mu \mathrm{m}$ ) relative to the parallel edge of the tapered face. A detailed description of the ULAM procedure can be found elsewhere. [9] The ultra-low-angle taper passing through the PVdF/PU coatings employed here were produced using an ultra-low-angle sectioning block possessing a $200 \mu \mathrm{m}$ rise, giving a theoretical taper angle of $\sim 0.33^{\circ}$.

\section{Surface Analysis by XPS.}

XPS analyses were performed on a Thermo VG Scientific (East Grinstead, UK) Sigma Probe spectrometer. The instrument employs a monochromated AlK $\alpha$ X-ray 
source $(\mathrm{hv}=1486.6 \mathrm{eV})$ which was used at $300 \mathrm{~W}(15 \mathrm{kV} \times 20 \mathrm{~mA})$. The area of analysis was approximately $500 \mu \mathrm{m}$ diameter for the PVdF topcoat and PU primer surfaces analysed. A $200 \mu \mathrm{m}$ diameter area of analysis and a $230 \mu \mathrm{m}$ interval size were employed for the PVdF/PU ULAM taper sample linescan analyses. The pass energy was set at $20 \mathrm{eV}$ for core level high-resolution spectra of all elements of interest and at $100 \mathrm{eV}$ for all survey spectra. Charge compensation was achieved using an electron flood gun. The coating samples were held in place on the instruments sample stage by a sprung $\mathrm{Cu} / \mathrm{Be}$ clip.

\section{Surface Analysis by ToF-SIMS.}

ToF-SIMS mass spectra analyses were performed on a VG Scientific (East Grinstead, UK) Reflectron ToF-SIMS spectrometer. This instrument is equipped with a MIG 300PB pulsed liquid gallium ion source and a two-stage reflectron time-of-flight analyser. Static SIMS conditions (ion dose $<10^{13}$ ions $/ \mathrm{cm}^{2}$ ) were employed with a 16 $\mathrm{keV}$ beam, delivering $2 \mathrm{nA}$ of current. The region of the surface analysed was a 500 $\mu \mathrm{m}$ wide square rastered area. Mass spectra in the mass range $0-400 \mathrm{~m} / \mathrm{z}$, in the positive ion acquisition mode were acquired. 


\section{Results and Discussion :}

The polyester/polyurethane based coating formulation constituted the model PU primer system on aluminium substrate. The said primer is based on a commercial, 'real world' formulation and hence is a complex mixture designed to produce a coating/paint that possesses a range of properties including adhesion, formability and corrosion resistance. In Figure 1 an XPS survey spectra and a positive ion ToF-SIMS mass spectrum of the air/coating surface of a PU primer coating without flow agent are presented. In the XPS survey spectra of the PU primer presented in Figure 1a, XPS signals characteristic of $\mathrm{C}(\sim 84 \%), \mathrm{N}(\sim 2 \%)$ and $\mathrm{O}(\sim 14 \%)$ are observed. Only these elements are present at the air/coating surface of the PU primer without flow agent. The positive ion mass spectrum (mass range $0-200 \mathrm{~m} / \mathrm{z}$ ) of the PU primer without flow agent presented in Figure $1 \mathrm{~b}$ is typical of aliphatic polymers. That is, the mass spectrum is dominated by peaks derived from organic fragments of the form $\mathrm{C}_{\mathrm{n}} \mathrm{H}_{\mathrm{m}}{ }^{+}$. Such fragments are common in all organic material systems SIMS mass spectra. However, the mass spectrum in Figure $1 \mathrm{~b}$ does contain a number of peaks characteristic of the PU primer. In particular the peaks observed at $104 / 5\left(\mathrm{C}_{7} \mathrm{H}_{4(5)} \mathrm{O}^{+}\right)$, $149\left(\mathrm{C}_{8} \mathrm{H}_{5} \mathrm{O}_{3}{ }^{+}\right)$and $193 \mathrm{~m} / z\left(\mathrm{C}_{10} \mathrm{H}_{9} \mathrm{O}_{4}{ }^{+}\right)$are diagnostic of a phthalate species [10] within the PU primer. The polyester/polyurethane resin, which is the principal component of the formulation, contains a phthalate moiety in the backbone, thus these peaks are diagnostic markers for the PU primer coating.

In Figure 2 an XPS survey spectra and a positive ion ToF-SIMS mass spectrum (mass range $0-200 \mathrm{~m} / \mathrm{z}$ ) of a PU primer coating are again presented. In this case however, 
the PU primer formulation contains a PDMS based flow agent additive. The flow agent itself is a thermally stable, polyester modified PDMS. In the XPS survey spectra presented in Figure 2a, XPS signals characteristic of $\mathrm{C}(\sim 70 \%), \mathrm{N}(\sim 2 \%)$ and O $(\sim 21 \%)$ are again observed, however, in addition to these elements, signals characteristic of $\mathrm{Si}(\sim 8 \%)$ are also observed at the PU primer surface. It is noted that the surface concentration of oxygen increases whilst that of carbon decreases upon addition of the PDMS based flow agent to the PU primer formulation. This result suggests segregation of the PDMS based flow agent to the surface of the PU primer as anticipated. If the surface was dominated by the silicon flow aid then the $\mathrm{Si}$ concentration would have been $19 \%$.

The ToF-SIMS mass spectrum presented in Figure 2b, obtained from the air/coating surface of the PU primer containing PDMS based flow agent is very different to that observed in Figure $1 \mathrm{~b}$ for the PU primer formulation without flow agent. The sequence of fragment peaks observed in Figure $2 \mathrm{~b}$ at $28\left(\mathrm{Si}^{+}\right), 29\left(\mathrm{SiH}^{+}\right), 43\left(\mathrm{SiCH}_{3}{ }^{+}\right)$, $73\left(\mathrm{Si}\left(\mathrm{CH}_{3}\right)_{3}{ }^{+}\right), \quad 133 \quad\left(\mathrm{Si}_{2} \mathrm{C}_{3} \mathrm{H}_{9} \mathrm{O}_{2}{ }^{+}\right), \quad 147 \quad\left(\left(\mathrm{CH}_{3}\right)_{3} \mathrm{SiOSi}\left(\mathrm{CH}_{3}\right)_{2}{ }^{+}\right)$and $191 \mathrm{~m} / \mathrm{z}$ $\left(\mathrm{Si}_{3} \mathrm{C}_{5} \mathrm{H}_{15} \mathrm{O}_{2}^{+}\right)$are diagnostic of PDMS. [10] These silicon containing peaks dominate the mass spectrum in Figure $2 \mathrm{~b}$ and the organic peaks associated with the PU primer itself are strongly attenuated. This result confirms that the PDMS based flow agent has segregated to the air/coating surface of the PU primer and now dominates the PU primers surface composition. Perruchot et al have demonstrated by angle resolved XPS that flow agents (including a PDMS-polyether type) when added to polymeric coating formulations generally form a segregation layer, $\sim 0.5-2.0 \mathrm{~nm}$ deep, at the 
surface of the coating. [3] It is reasonable to assume that the PDMS based flow agent employed here has acted in a similar manner and formed a segregation layer at the air/coating surface of the PU primer. N.B. nitrogen is seen in XPS but not SIMS and more of it than in polyacrylate flow aid systems. Hence the flow aid layer is very thin. This is substantiated by the low concentration of silicon detected ( $8 \%$ vs $19 \%)$.

Having characterised the PU primer surfaces, a PVdF based topcoat was applied to each of the PU primer formulations and the resulting PVdF topcoat air/coating surfaces investigated by XPS and ToF-SIMS. Due to its similarity to a commercial system the model PVdF topcoat formulation employed is a complex mixture containing a number of components and additives. An XPS survey spectra and a positive ion ToF-SIMS mass spectrum obtained from the air/coating surface of a PVdF topcoat applied to a PU primer without flow agent are presented in Figure 3. In Figure 3a the XPS survey spectra contains XPS signals characteristic of C ( 77\%), O $(\sim 18 \%)$ and $\mathrm{F}(\sim 5 \%)$, only these elements are present at the air/coating surface of the PVdF topcoat. The complementary ToF-SIMS mass spectrum in Figure $3 b$ of the $\mathrm{PVdF}$ topcoats air/coating surface is again typical of an aliphatic organic polymer as it is dominated by common organic fragments of the general form $\mathrm{C}_{\mathrm{n}} \mathrm{H}_{\mathrm{m}}{ }^{+}$. However, a number of fragment peaks characteristic of the PVdF resin (the principal component of the formulation) are observed at $31\left(\mathrm{CF}^{+}\right), 95\left(\mathrm{C}_{3} \mathrm{H}_{2} \mathrm{~F}_{3}{ }^{+}\right), 113\left(\mathrm{C}_{3} \mathrm{HF}_{4}^{+}\right), 127$ $\left(\mathrm{C}_{4} \mathrm{H}_{3} \mathrm{~F}_{4}{ }^{+}\right)$and $133 \mathrm{~m} / z\left(\mathrm{C}_{3} \mathrm{H}_{2} \mathrm{~F}_{5}{ }^{+}\right)$. [10] XPS and ToF-SIMS spectra obtained from a sample in which the PVdF topcoat was applied directly to an aluminium substrate (i.e. no primer was applied) resulted in spectra more or less identical to those 
observed in Figure 3. These results indicate the PVdF topcoats air/coating surface is highly organic in nature and that some of the PVdF resin is incorporated into the air/coating surface. Previous results have indicated higher values of fluorine at the air/coating interface indicating, that in this case, the surface is dominated by something other than PVdF, probably the acrylic resin.

An XPS survey spectra and a positive ion ToF-SIMS mass spectrum obtained from the air/coating surface of the PVdF topcoat applied to a PU primer containing the PDMS based flow agent are presented in Figure 4. It is observed that the spectra in Figure 4 are very similar to those in Figure 3 as might be expected given that both were acquired from the air/coating surface of PVdF topcoats. However, it is noted in the XPS survey scan in Figure 4a that small but discernible peaks characteristic of silicon (Si2p $\sim 100 \mathrm{eV}, \mathrm{Si} 2 \mathrm{~s} \sim 150 \mathrm{eV}$ ) are present. The elemental composition of the PVdF topcoats air/coating surface is $\mathrm{C}(\sim 71 \%), \mathrm{O}(\sim 21 \%), \mathrm{F}(\sim 5 \%)$ and $\mathrm{Si}(\sim 3 \%)$ when the PVdF topcoat is applied to the PU primer containing the PDMS flow agent. The XPS data showing silicon present at the PVdF topcoats air/coating surface in combination with the small increase observed in oxygen concentration at the PVdF topcoats air/coating surface suggests that the PDMS based flow agent may be present at this surface.

In the positive ion ToF-SIMS mass spectrum in Figure $4 \mathrm{~b}$ the PVdF topcoats air/coating surface is as before dominated by ions from an aliphatic polymer. Fragment peaks characteristic of the PVdF resin are observed in Figure $4 \mathrm{~b}$ at 31 
$\left(\mathrm{CF}^{+}\right), \quad 113\left(\mathrm{C}_{3} \mathrm{HF}_{4}^{+}\right), 127\left(\mathrm{C}_{4} \mathrm{H}_{3} \mathrm{~F}_{4}^{+}\right)$and $133 \mathrm{~m} / z\left(\mathrm{C}_{3} \mathrm{H}_{2} \mathrm{~F}_{5}^{+}\right)$. [10] However, comparison of the mass spectrum in Figure $4 \mathrm{~b}$ with that in Figure $3 \mathrm{~b}$ (for the PVdF topcoat on PU primer without flow agent), reveals the presence of additional peaks at 73, 147 and $191 \mathrm{~m} / z$. These peaks are attributed to $\mathrm{Si}\left(\mathrm{CH}_{3}\right)_{3}{ }^{+},\left(\mathrm{CH}_{3}\right)_{3} \operatorname{SiOSi}\left(\mathrm{CH}_{3}\right)_{2}{ }^{+}$ and $\mathrm{Si}_{3} \mathrm{C}_{5} \mathrm{H}_{15} \mathrm{O}_{2}{ }^{+}$molecular fragments respectively and are diagnostic of a PDMS based material. Thus the presence of the PDMS based flow agent at the PVdF topcoats air/coating surface is confirmed. These results suggest that the PDMS based flow agent has detached itself from the PU primer at the PVdF/PU interface, dissolved into the PVdF topcoat bulk and has migrated through the PVdF topcoat such that it is observed at the PVdF topcoats air/coating surface. The XPS quantification indicates that the concentration is a quarter of that at the primer surface.

With the results from the above studies suggesting migration of the PDMS based flow agent from the PU primer surface into the PVdF topcoat (such that PDMS is observed at the topcoats air/coating surface), ULAM was employed to prepare a ultra-lowangle taper that passed through the PVdF topcoat and into the underlying PU primer. A schematic depicting the apparatus employed in the ULAM tapering of coating specimens on a metal substrate is presented in Figure 5. The concept underlying the formation of ultra-low-angle tapers through polymeric coating by ULAM is very simple; a specimen is mounted on an angled sectioning block possessing an ultra-lowangle taper on one of its faces. This specimen is then presented to the microtome knife such that sectioning of the polymeric coating by the microtome knife imparts a 
geometrically well-defined, ultra-low-angle taper through the coating. [8] Inset in Figure 5 is a digitally recorded optical image of a $\mathrm{PVdF} / \mathrm{PU}$ coating on aluminium substrate that has undergone ULAM tapering. The ultra-low-angle taper (as indicated by the arrow in the inset in Figure 5) cuts the blue PVdF topcoat's air/coating surface, passes through the bulk of the PVdF topcoat and terminates in the bulk of the yellow PU primer. The image inset in Figure 5 demonstrates that ULAM can be employed to prepare a taper that passes through the entire length of a coating, in the case of the PVdF topcoat employed here the PVdF topcoat film depth is $20-22 \mu \mathrm{m}$. Such tapers may then be employed to acquire compositional depth profiles with good depth resolution [11] over analysis lengths greater than those available to more conventional depth profiling techniques.

Having fabricated an ultra-low-angle taper that passes through the PVdF/PU multilayer coating a compositional depth profile describing changes in the concentration of $\mathrm{C}, \mathrm{O}, \mathrm{F}, \mathrm{N}$ and $\mathrm{Si}$ along the ULAM taper was obtained by XPS linescan. The ULAM taper was produced using an angled sectioning block containing a $200 \mu \mathrm{m}$ taper, providing a theoretical taper angle of $0.33^{\circ}$. For the XPS linescan analysis an X-ray spot $200 \mu \mathrm{m}$ in diameter and a $230 \mu \mathrm{m}$ linescan interval size were employed. This combination of taper angle and linescan interval provides a theoretical analysed depth of $\sim 1.25 \mu \mathrm{m}$ per analysis point (where the XPS analysis is performed on the ULAM taper as it descends through the coating bulk). A compositional depth profile describing changes in elemental concentration (in atomic \%) through the PVdF/PU coating is presented in Figure 6. The analysis depth scale 
(x-axis) traditionally used for compositional depth profiles has been replaced with sequential analysis point numbering. This scale has been selected because not all of the analysis points in Figure 6 were acquired on the ULAM taper. Analysis points 117 were acquired on the ULAM taper, however, analysis points 18-20 were acquired by the XPS linescan at the PVdF topcoats air/coating surface.

In Figure 6, it is observed that the changes in elemental composition follow a general profile; that is analysis point's 1-3 exhibit similar elemental concentration values, consistent with each of these analysis points being acquired in the PU primer region of the ULAM taper. Concentration values for each element, except silicon, for analysis points 6-17 fall within a narrow range for each individual element; this is consistent with each of these data points being acquired in the region of the ULAM taper that spans the PVdF topcoats bulk. However, the fluorine concentration is unusually low as the bulk concentration is normally closer to $33 \%$. Analysis points 18-20 exhibit similar elemental concentrations for each of the individual elements examined, this is as anticipated given that these analysis points were acquired on the PVdF topcoats air/coating surface. The depth profile for fluorine in Figure 6 exemplifies the general trend observed. For analysis points 1-3 in the PU primer the fluorine concentration is 0 as the primer formulation contains no fluorine bearing components. Between analysis points 6-17 the fluorine concentration is steady around $18 \pm 3 \%$, consistent with the topcoat bulk. For analysis points $18-20$ the fluorine concentration falls to $\sim 5 \%$, consistent with these data points being acquired at the PVdF topcoats air/coating surface. The exception to this general trend in Figure 6 is 
the depth profile for silicon. It is observed in Figure 6 that the silicon concentration increases as the linescan analysis progresses through the PVdF topcoat and that the silicon concentration maximum is observed at the analysis points obtained at the PVdF topcoats air/coating surface.

In Figure 7 the silicon concentration depth profile (from Figure 6) has been extracted and the data re-scaled to aid analysis. It is observed in Figure 7 that in the PU primer region of the ULAM taper (analysis points 1-3) the silicon concentration is steady at $\sim 0.5 \%$. This may be the result of silicon containing additives (other than the PDMS flow agent such as a matting agent) forming part of the PU primer or may be due to a fraction of the PDMS based flow agent that has not migrated into the PVdF topcoat. However, the silicone flow aid was only added at a concentration of $0.05 \%$ and the silicon content is only $19 \%$ of this giving a value of $0.01 \%$. This suggests that other silicon containing species are contributing to the signal. But previous analysis have not revealed such a contribution from such things as matting agents and the matting agent was again added at a low concentration.

Between analysis points 4 and 11 in Figure 7 the silicon concentration is fairly stable at $1 \pm 0.3 \%$. However, beyond analysis point 11 a rapid increase in silicon concentration is observed in Figure 7. Finally, the silicon concentration reaches a maximum of $\sim 3 \%$ at the PVdF topcoats air/coating surface. The observed changes in silicon concentration with depth and the shape of the curve in Figure 7, are indicative of the formation of a silicon concentration gradient within the bulk of the PVdF 
topcoat. The shape of the silicon concentration profile in Figure 7 is clear evidence that the process at work is not diffusion driven, as these results show a clear example of "uphill" diffusion. These results suggest that the PDMS based flow agent used in the PU primer formulation is highly mobile. The PDMS based flow agent segregation layer known to form at the PU primer air/coating surface has detached from the PU primer and migrated into the PVdF topcoat. Furthermore, not only has the PDMS based flow agent migrated into the PVdF topcoat but it is segregating to the PVdF topcoats air/coating surface where it presumably has an effect upon the properties exhibited by this surface. Such segregation of a PDMS based flow agent to the air/coating surface can be understood in terms of the need of the lowest surface free energy component of the coating (in this case the PDMS) to segregate to the air/coating surface (Gibbsian segregation). Thus the PDMS based flow agent that has migrated into the PVdF topcoat and segregated to the air/coating surface of the PVdF topcoat in order to minimise the surface free energy of the coating and by doing so has created the silicon concentration gradient observed in Figure 7. A similar result has been reported by Hinder et al, where studies on adhesion failure in multilayer organic coatings indicated migration and segregation of a flow agent, included in the PU primer, into a PVdF topcoat. [12] The difficulties with this conventional explanation are that the silicone was added at a very low concentration to the primer and that the step increase would be expected to occur just at the PVdF/air interface not 10 microns below it. 
High silicon concentrations at the PVdF/air interface could be explained by the flow aid dissolving and segregating to this interface driven by the reduction in surface tension that would then occur. However, the only way to explain the distribution observed is to invoke a migration mechanism that occurs during and after the microtoming action. That is a substantial portion of the flow aid on the surface of the primer dissolves into the PVdF topcoat and segregates to the PVdF/air interface. Once the coating is cut on the microtome the silicone migrates from the top of the coating to a distance of about $30 \mu \mathrm{m}$ along the freshly cut face at the same time the silicone remaining at the interface migrates in both directions. The result suggests several dynamic processes are occurring which could only be discerned with time resolved application procedures. Firstly, the flow aid must dissolve into the PVdF at a certain rate and then it vacates the interfacial region and segregates to the air/coating surface. The dissolution process is slowed by the concentration of the flow aid in the interfacial region of the liquid $\mathrm{PVdF}$ and by the reduced solvent concentration caused by the evaporation of this component during the heating of the panel to its peak metal temperature. Some of the silicone may have become chemically bound on the primer surface but again this needs further investigation.

\section{Conclusions :}

The XPS and TOF-SIMS characterisation of a model PU primer based on a 'real world' commercial formulation, with and without the addition of a PDMS based flow agent, has been demonstrated. It was observed that the inclusion of the PDMS based 
flow agent in the PU primer formulation results in the segregation of the flow agent to the PU primer air/coating surface where it dominates the PU primer surface composition. XPS and ToF-SIMS characterisation of the air/coating surface of a model PVdF topcoat (itself based on a 'real world' commercial formulation) applied to the PU primer (with and without flow agent) revealed the presence of PDMS material at the PVdF topcoats air/coating surface even though no PDMS based components or additives are included in the PVdF topcoat formulation. These results suggest migration of the PDMS based flow agent from the PU/PVdF interface into and through the PVdF topcoat.

The fabrication of a ULAM taper passing through the entire depth of the PVdF topcoat $(\sim 20 \mu \mathrm{m})$ and into the underlying PU primer enabling compositional depth profiling over an analysis depth of $\sim 25 \mu \mathrm{m}$ was demonstrated. Analysis of the silicon concentration profile indicates that the PDMS based flow agent does not diffuse into the PVdF topcoat after gelation but migrates into the PVdF topcoat during the "curing process' and segregates to the PVdF topcoats air/coating surface. In addition, the shape of the silicon concentration profile indicates that the segregation of the PDMS based flow agent to the PVdF topcoats air/coating surface results in the formation of a silicon concentration gradient $(\sim 10 \mu \mathrm{m}$ deep) running from the PVdF topcoat bulk to the air/coating surface. Such migration and segregation phenomena based on material mobility and the minimisation of surface free energies may have profound implications for the scientists and engineers involved in formulating coatings and paints. 


\section{Acknowledgements :}

The authors acknowledge the financial support of the EPSRC (grant no. GR/N65745).

\section{References :}

[1] Leadley SR, Watts JF, Blomfield CJ, Lowe C, Surface and Interface Analysis 26 (1998) 444.

[2] Watts JF, Abel M-L, Perruchot C, Lowe C, Maxted JT, White RG, J. Electron Spectrosc. Relat. Phenom. 121 (2001) 233.

[3] Perruchot C, Abel M-L, Watts JF, Lowe C, Maxted JT, White RG, Surface and Interface Analysis 34 (2002) 570.

[4] Hinder SJ, Lowe C, Maxted JT, Watts JF, Surface and Interface Analysis 36 (2004) 1575.

[5] Horgnies M, Darque-Ceretti E, Combarieu R, Progress in Organic Coatings 47 (2003) 154.

[6] Haack LP, Straccia AM, Holubka JW, Bhurke A, Xie M, Drzal LT, Surface and Interface Analysis 29 (2000) 829.

[7] Hajas J. In Additives for Coatings. Bieleman J (ed.). Wiley-VCH Verlang: Weinheim, Germany, 2000; Chapter 6.1 Levelling Additives, 163-179 .

[8] Hinder SJ, Watts JF, Lowe C, Surface and Interface Analysis 36 (2004) 1032.

[9] Hinder SJ, Watts JF, Maxted JT, In press Journal of Materials Science 2005.

[10] In The Wiley Static SIMS Library (Version 2), vol. 2. Vickerman JC, Briggs D, Henderson A (eds). John Wiley: Chichester, 1999; Organic Materials - Homo Polymers.

[11] Guichenuy M, Watts JF, Abel M-L, Brown AM, Audenaert M, Amouroux N, Surface and Interface Analysis 36 (2004) 685.

[12] Hinder SJ, Lowe C, Maxted JT, Watts JF, Accepted for publication in Progress in Organic Coatings, November 2004. 


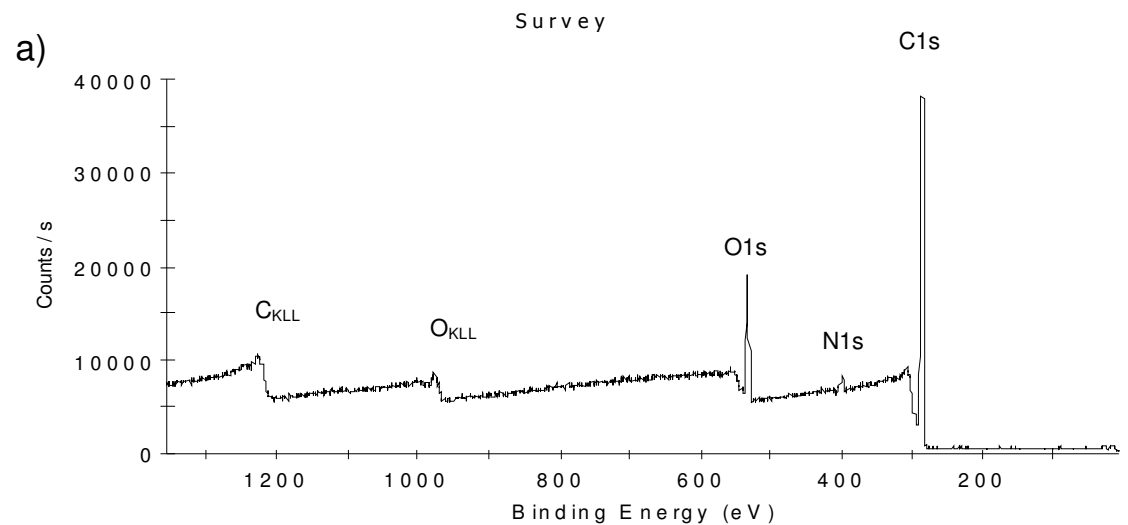

b)

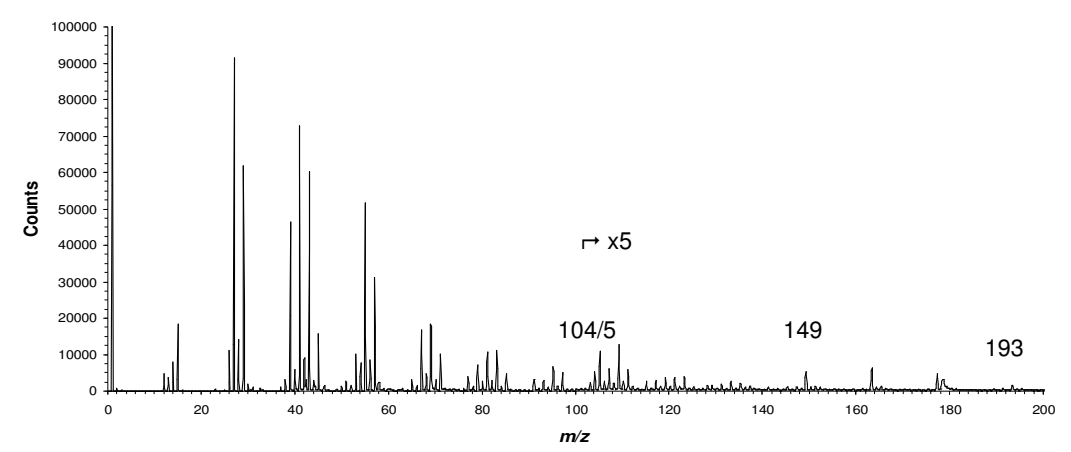

Figure 1. a) XPS survey spectra and b) positive ion ToF-SIMS mass spectrum of the surface of the pristine PU primer without the silicon containing flow aid. 
a)

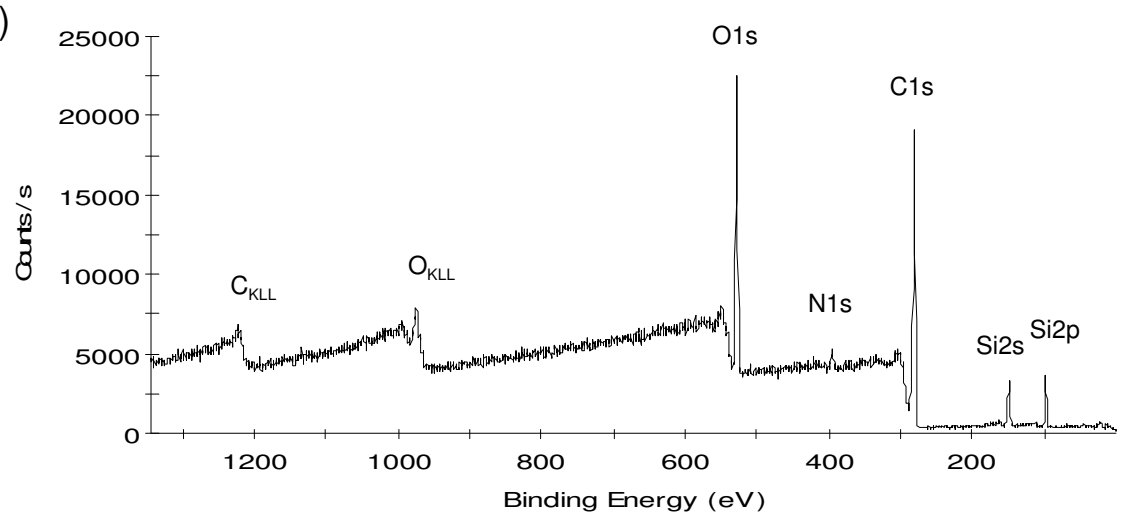

b)

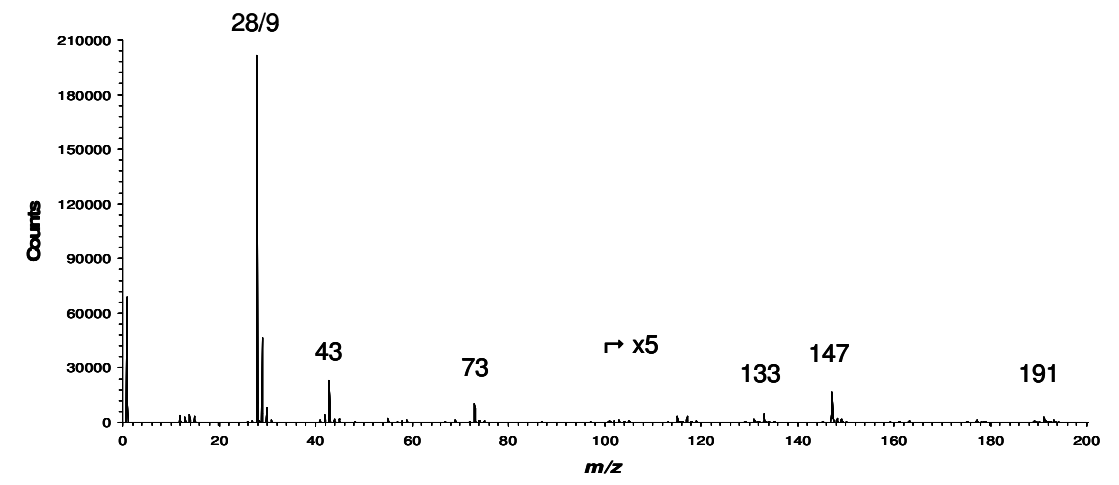

Figure 2. a) XPS survey spectra and b) positive ion ToF-SIMS mass spectrum of the surface of the PU primer with the Si containing flow aid added to the formulation. 


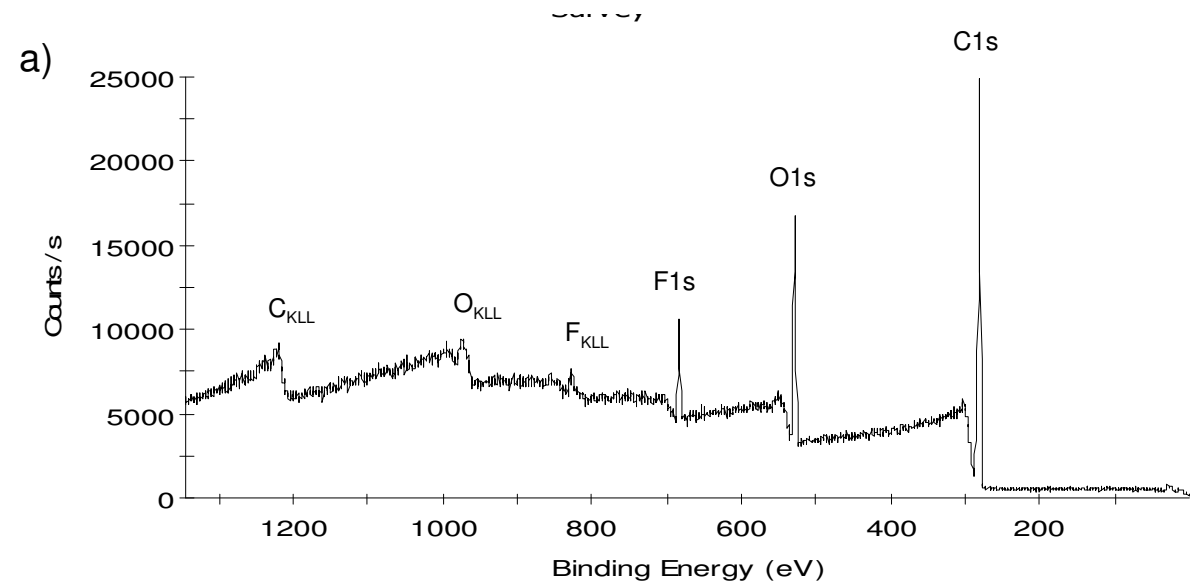

b)

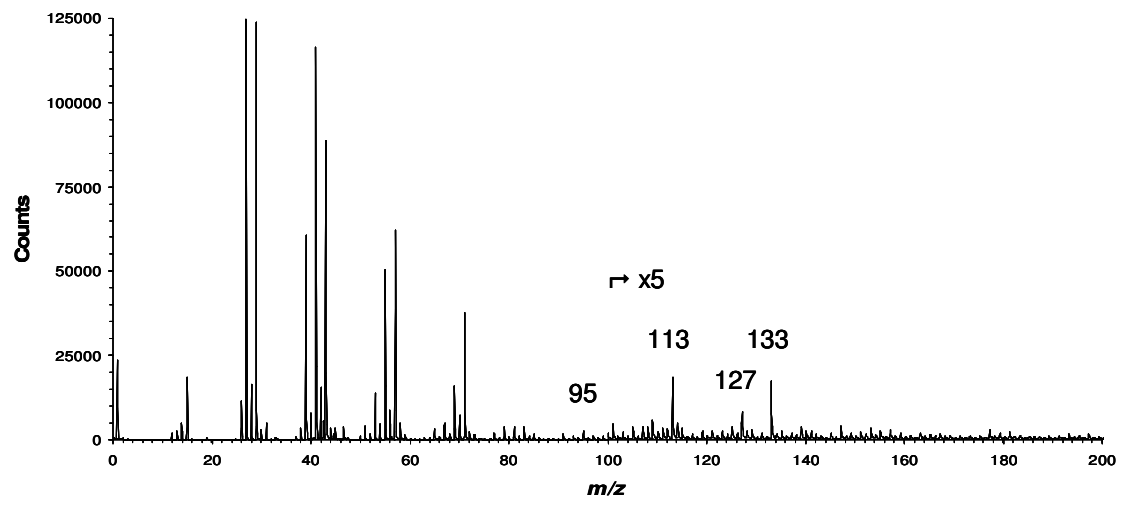

Figure 3. a) XPS survey spectra and b) positive ion ToF-SIMS mass spectrum of the PVdF topcoat air/coating surface. The PVdF based topcoat had been applied to the PU primer that contained no flow aid. 
a)

C1s

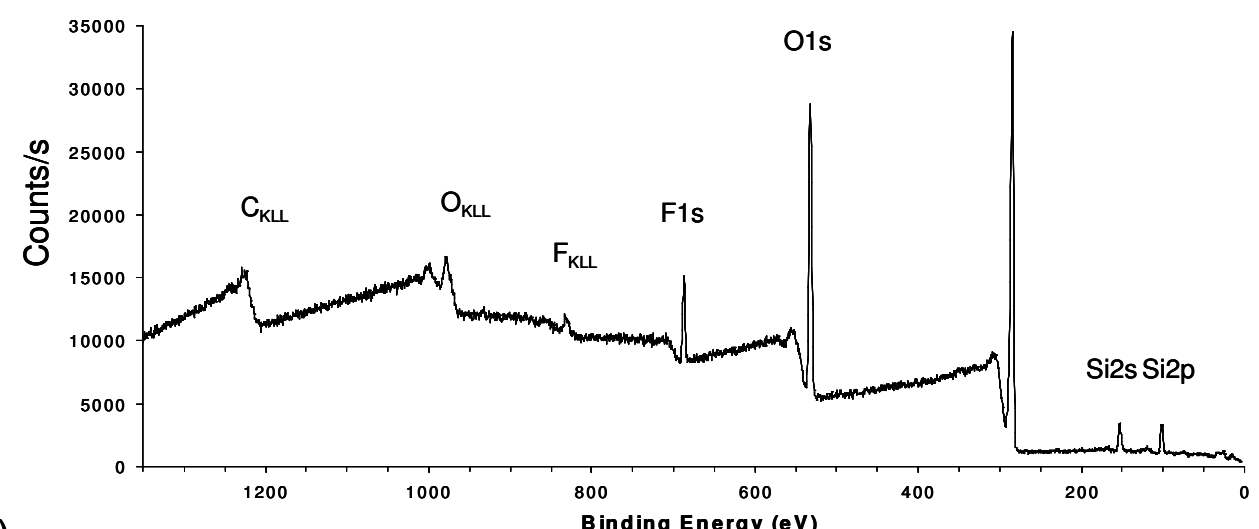

b)

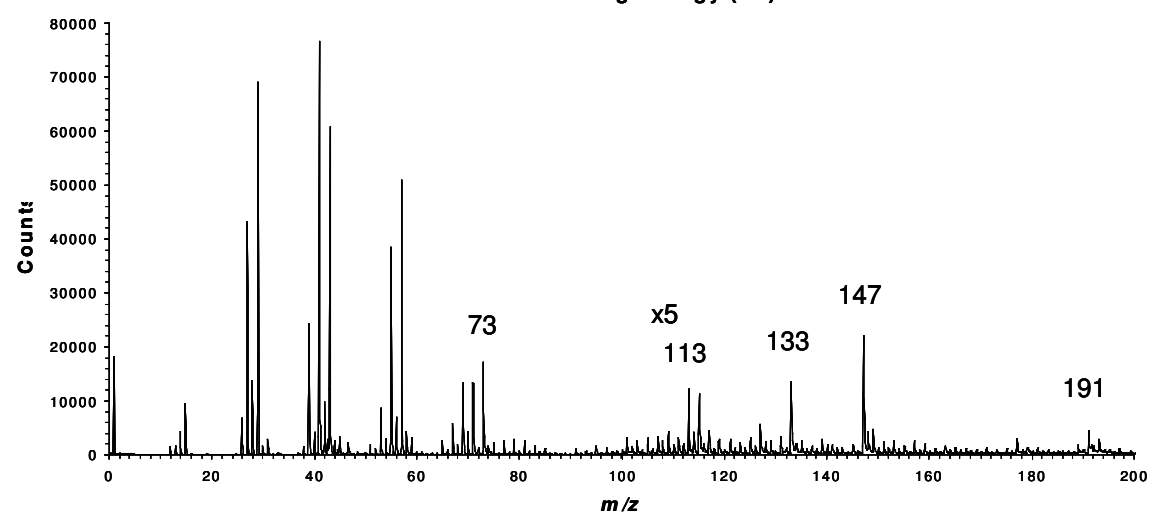

Figure 4. a) XPS survey spectra and b) positive ion ToF-SIMS mass spectrum of the PVdF topcoat air/coating surface. The PVdF topcoat was applied to the PU primer containing the Si based flow aid. 


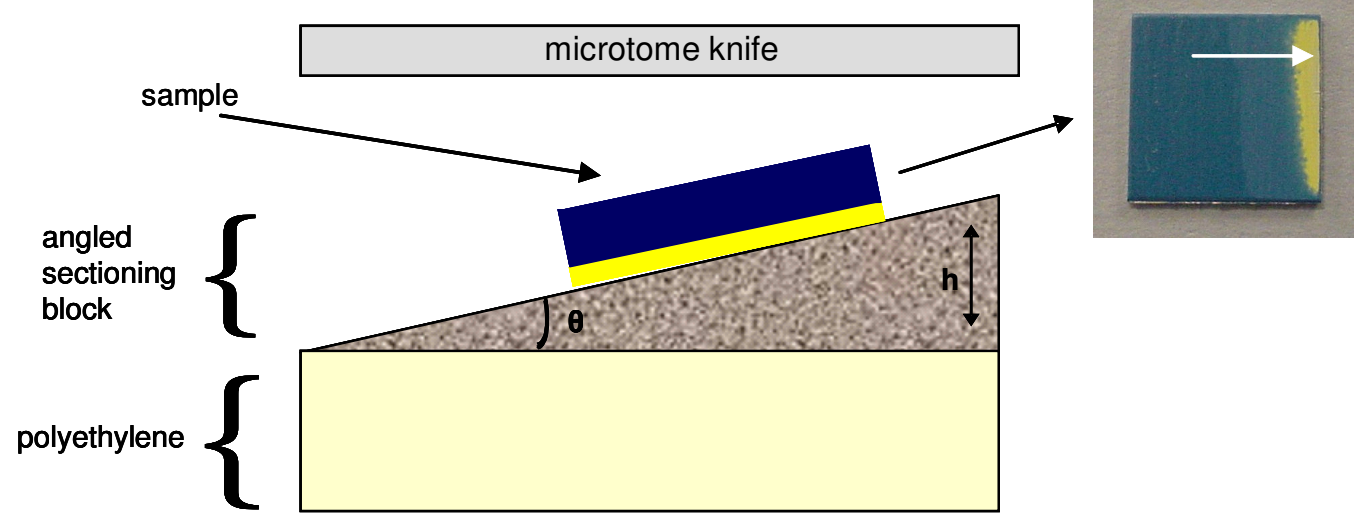

Figure 5. Schematic depicting the concept of ultra-low-angle microtomy employed to impart a ultra-low-angle taper through a multilayer, polymeric coating system. Inset is a digitally recorded optical image of a PVdF/PU multilayer coating taper passing through the PVdF topcoat (blue) into the underlying PU primer (yellow). 


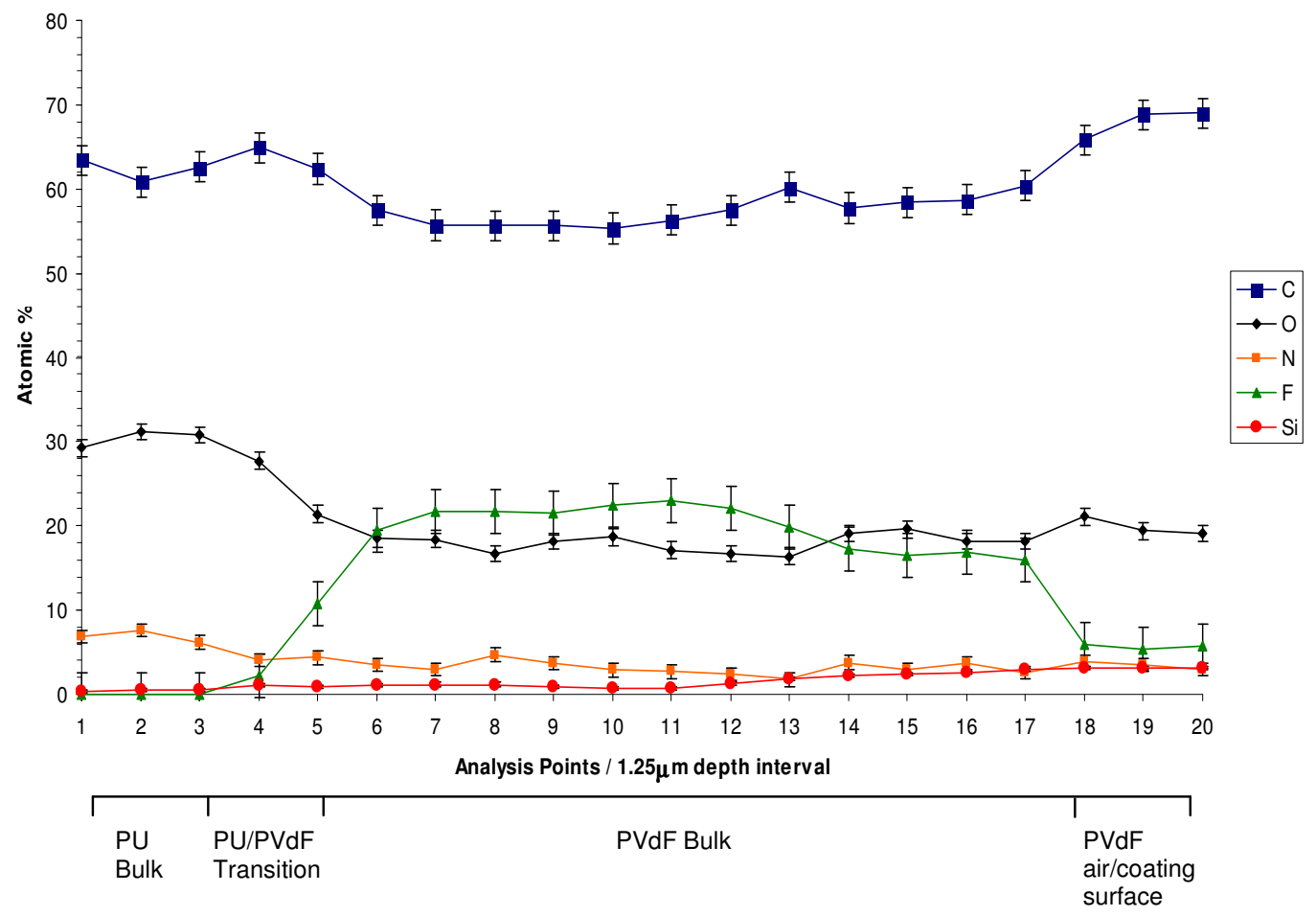

Figure 6. A compositional depth profile through a PVdF/PU multilayer, organic coating system. The depth profile was obtained by performing an XPS linescan analysis along a ULAM produced taper through the multilayer coating system. 


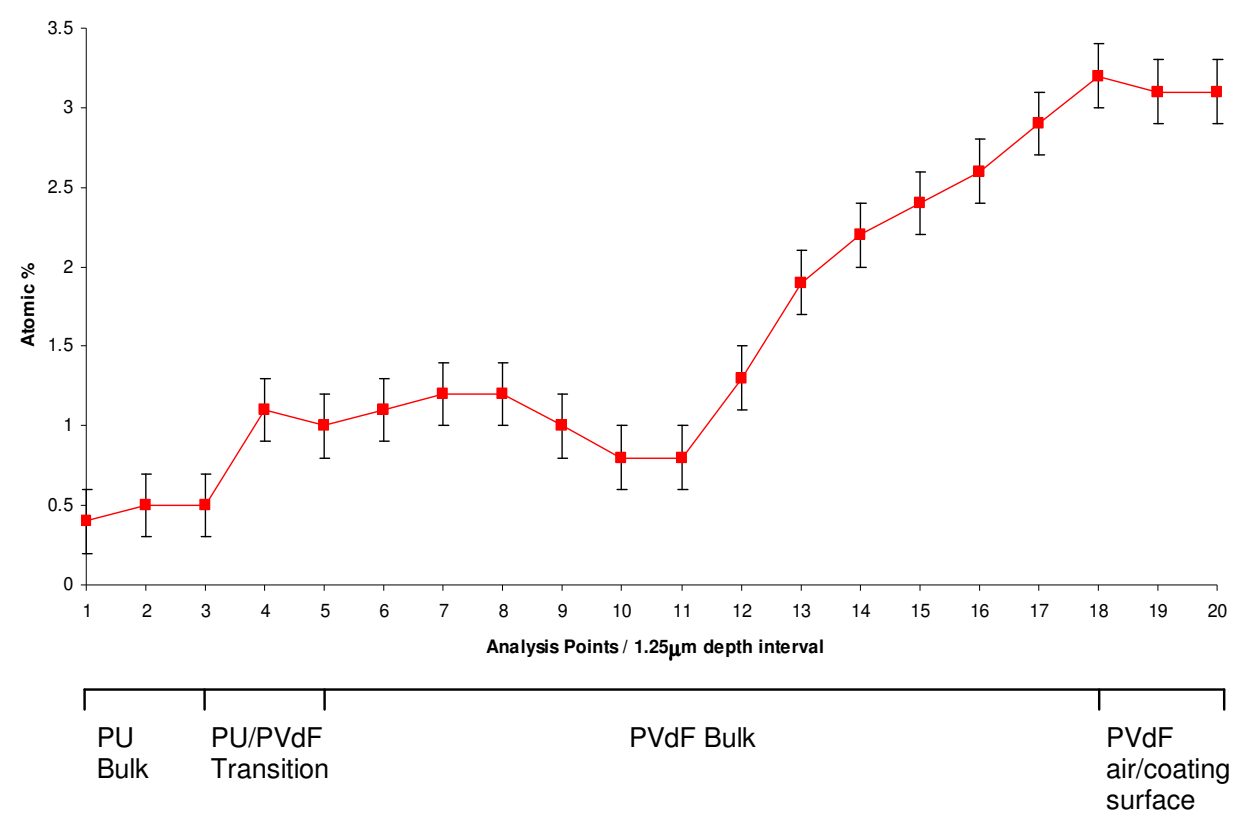

Figure 7. A compositional depth profile through a PVdF/PU multilayer, organic coating system showing changes in silicon concentration (in at. \%). 